International Journal of

BioScience and Applications

\title{
The Relationship between the Effectiveness of Virtual Reality Experience on Maritime Safety and the Intention to Re-Participate
}

\begin{abstract}
Sung-Duck Kim ${ }^{1}$, Joo-Yung Kim*
${ }^{1}$ Division of Sport Science, Baekseok University, 76 Munam-ro Dongnam-gu Cheonan-si Chungcheongnam-do, 330-704, South Korea

*Division of Sport Science, Baekseok University, 76 Munam-ro Dongnam-gu Cheonan-si Chungcheongnam-do, 330-704, South Korea

Abstract

The purpose of this study is to investigate the efficiency of safety awareness of VR experience programs for marine safety and the participants' re-participating behavior. This would emphasize the need for maritime safety experience education, and contribute to preparing basic data for diversification of maritime safety VR contents. From June to August 2021, five of maritime safety experience facilities were visited to target users of VR programs. A total of 350 data were collected using the convenient sampling method, and 295 data were finally used for data analysis. As a result, VR experience for maritime safety had a positive effect on the participants' maritime safety awareness and re-participation behavior. This study could be meaningful in terms of highlighting the need to develop safety programs, and to expand education in South Korea, where three sides are the sea. In addition, this study emphasized the necessity of producing and operating various contents and programs based on VR.
\end{abstract}

\section{Index Terms}

Maritime safety, Virtual reality, Re-participation behavior, Education, Program

\footnotetext{
Corresponding author : Joo-Young, Kim kjm3409@naver.com

- Manuscript received July 15, 2021.

- Revised August 10, 2021 ; Accepted September 1, 2021.

- Date of publication September 30, 2021

(C) The Academic Society of Convergence Science Inc.

2619-8363 @ 2021 IJBSA. Personal use is permitted, but republication/redistribution requires IJBSA permission.
} 



\section{INTRODUCTION}

The interest and support of the Korean government for the marine industry are increasing. In recent years, especially interest in marine leisure sports is increasing in various fields, due to the diversification of the type of marine industry. In fact, the number of leisure sports visitors increased from about 720,000 in 2013 to about 950,000 in 2017, and the number of experience sites increased from 48 in 2014 to 64 in 2017 [1]. However, compared to the development of various marine industries and marine leisure sports, it would be difficult to find a systematic safety education and policy-oriented approach to participation in marine leisure sports.

According to the law related to maritime safety, there is a limitation in that marine leisure activities cannot be safely applied, so it is not sufficient to stably support increasing marine activities. Because developed countries usually carry out active leisure activities using passenger ships, fishing boats, and leisure engines in the activated marine industry environment [2], Korea also needs to prepare for marine safety accidents.

Generally, safety accidents that occur in the sea are quite large, unlike general accidents, so it could be best to prevent accidents from occurring. Thus, it is necessary to educate individuals in crisis situations on their usual coping ability to switch from dangerous situations to safe situation [3]. Despite the desperate need for such important safety education, there is a characteristic that when an accident occurs, it becomes a social issue for a while, and then disappears again, Currently, maritime safety education in Korea is only trying to promote safety awareness by forming the Maritime Safety Practice Headquarter since 2014.

There is a limitation in that only easy education, such as wearing a life vest is provided in the actual educational field. However, as the necessity and effectiveness of safety education through some experiential educations have recently expanded [4], the need for safety education through experiential education by life cycle has been suggested. In particular, workshops and marine education have recently been held, and the need for marine safety education has been emphasized. In addition, it is reported that the Ministry of Oceans and Fisheries actively conducts maritime safety education by providing marine survival experience centers and virtual reality (VR) experience programs through visiting maritime safety experience facility programs [2].

Meanwhile, previous studies related to marine disasters are generally conducted on disaster tools, disaster rescue activities and disaster prevention activities targeting sailors and ship crews [5]. However, it is difficult to find empirical studies on how to respond to safety in the event of a marine disaster. In addition, research on the efficiency of theoretical education and hands-on practice, improvement measures of water safety education, and disaster risk perception evaluation was conducted to analyze risk disasters [6-8].

However, the previous studies estimate that the experience of maritime safety is limited to text, image and video-oriented experience education, which is significantly different from the experience education of maritime safety experienced in VR. Since general education can lead to injury and loss of life, virtual safety experience education for marine accidents is more meaningful.

Therefore, the purpose of this study is to investigate the efficiency of safety awareness of VR experience programs for marine safety and the participants' re-participating behavior. This would emphasize the need for maritime safety experience education, and contribute to preparing basic data for diversification of maritime safety VR contents. Specific research questions to achieve the research purpose are as follows.

H1: VR experience program for maritime safety will be effective in the participants' awareness of maritime safety.

H2: The participants' awareness of maritime safety in VR experience program for maritime safety will affect their re-participation behavior.

\section{MATERIALS AND METHODS}

\section{A. Participants and procedure}

This study set the population of participants who participated in the Marine Safety Experience Project organized by the Ministry of Oceans and Fisheries and the Korea Maritime Transportation Safety Authority in 2021. Specifically, from June to August 2021, five maritime safety experience facilities nationwide were visited to target users of VR. As for the sampling method, a total of 350 data were collected using the convenient sampling method, and 295 data were finally used, excluding 55 data of unfaithful data such as repeatedly indicating the same question. The general characteristics of the research subject are shown in Table 1 . 
Table 1. Characteristics of the participants

\begin{tabular}{|c|c|c|c|}
\hline $\begin{array}{c}\text { Latent } \\
\text { variable }\end{array}$ & Measured variable & Number & Ratio(\%) \\
\hline \multirow{2}{*}{ Gender } & Male & 140 & 47.5 \\
\hline & Female & 155 & 52.5 \\
\hline \multirow{3}{*}{ Age } & Under 19 years of age & 147 & 50 \\
\hline & 20 to 39 yearsold & 56 & 19 \\
\hline & Over 40 years of age & 93 & 31 \\
\hline \multirow{3}{*}{ Job Type } & Student & 156 & 52.7 \\
\hline & House Wife & 35 & 11.8 \\
\hline & Office Worker & 105 & 35.5 \\
\hline \multirow{2}{*}{$\begin{array}{c}\text { Marriage } \\
\text { status }\end{array}$} & Single & 130 & 43.8 \\
\hline & Maried & 166 & 56.2 \\
\hline \multirow{2}{*}{$\begin{array}{l}\text { participation } \\
\text { status }\end{array}$} & First & 255 & 86.1 \\
\hline & OverSecond & 41 & 13.9 \\
\hline \multirow{5}{*}{$\begin{array}{c}\text { participation } \\
\text { Phace }\end{array}$} & Yusoo & 30 & 10.2 \\
\hline & Tongyoung & 32 & 10.8 \\
\hline & Name-lland & 122 & 41.2 \\
\hline & Umsung & 38 & 12.8 \\
\hline & Uljoo & 74 & 25 \\
\hline
\end{tabular}

\section{B. Measures}

The questionnaire consisted of 6 demographic characteristics, 15 maritime safety virtual experience recognition, 1 benefit of VR experience program, 3 safety consciousness effects through marine safety virtual experience, and 3 questions asking for overall satisfaction and re-participation in the experience program.

The contents of maritime safety education for this study were based on virtual experiences on crisis response, escape after movement, and survival swimming in the event of a marine accident.

Commitment into VR refers to the degree of immersion in activities experienced virtually. In this study, based on the research of Csikszentmihalyi (2000) [9], which conceptualized commitment as a flow, the instrument [10] used to verify the effectiveness of safety education at construction sites was modified to suit the contents of this study. The Cronbach's alpha value of commitment in VR was .837 , sufficiently securing internal consistency.

The effect of safety education based on VR is measured whether it is applicable to the field. The field application to safety consists of a 3D modeling (BIM) basis beyond document, photo, and video training. In particular, the effect of safety education through Safety BIM fused with VR was verified [10], and in this study, the safety effect of marine activities was modified to suit the purpose of the study and composed of 5 questions. The Cronbach's alpha value of the factor was secured as .808, confirming internal consistency.

The efforts to overcome and respond to risks in the actual living field are limited to hands-on education to solve the situation. Therefore, content for pre-safety effects for the initiation and overcoming of risk factors is important [11]. In this study, the instrument [10] that verified the safety effect of VR was modified to suit the purpose of the study, and the Cronbach's alpha value of the question was .872 , thereby securing internal consistency.

In this study, the questions were composed of three efficiency factors suggested in the study on marine disaster experience education and the effectiveness of maritime safety awareness [3]. Specifically, the effects of cultivating safety awareness, cultivating crisis response capabilities, and recognizing emergency situations were measured, and the Cronbach's alpha value of the constructed questions was .848.

Re-participation behavior, which means satisfaction with experiential education using VR, willingness to re-participate, and recommending the education to others, was investigated by modifying the measurement tool of the study to suit the purpose of this study [12]. Specifically, it consisted of four questions asking for overall satisfaction, plans and intentions to participate again, and positive delivery to others, and the Cronbach's alpha value of the subfactor was .834 .

\section{Validity and reliability}

This study exploratory analyzed the effectiveness of marine safety experience education by a group of three experts, including experiential education experts in the maritime safety area, Ph.D. and professors in charge of marine and water sports safety.

After that, the contents of the questionnaire presented in the preceding study were modified to suit this study and the validity was verified. The questionnaires were distributed and collected to secure recruitment validity through confirmatory factor analysis.

As a result of confirmatory factor analysis, the model was found to be inappropriate $\left(x^{2}=273.992\right.$, $\mathrm{df}=125, \mathrm{p}<.000)$. However, model fit showed SRMR $=.040, \quad$ RMSEA $=.090, \quad$ TLI $=.939$ and 
$\mathrm{CFI}=953$, which means that goodness-of-fit index reached the recommended level [13].

Because the construct reliability value (CR) was from .831 to .952 , internal consistency was secured by sufficiently satisfying the criteria of 0.6 [14]. In addition, average variance extracted (AVE) was also .828 to .959 , indicating that concentrated validity was secured by satisfying the criteria [15]. Therefore, all standardized path coefficients are statistically significant $(p<) .001)$ confirmed that the factors were loaded and used as a whole model analysis $<$ Table $2>$.

Table 2. Result of confirmatory factor analysis

\begin{tabular}{|c|c|c|c|c|c|}
\hline \multicolumn{2}{|c|}{ Factor } & Estimates & C.R. & AVE & Cronbach's \\
\hline \multirow{15}{*}{$\begin{array}{c}\text { Water } \\
\text { Safety } \\
\text { Virtual } \\
\text { Reality } \\
\text { Experience }\end{array}$} & FVE2 & .845 & \multirow{3}{*}{.951} & \multirow{3}{*}{.866} & \multirow{3}{*}{.869} \\
\hline & FVE4 & .838 & & & \\
\hline & FVE5 & .813 & & & \\
\hline & VRA6 & .745 & \multirow{3}{*}{.952} & \multirow{3}{*}{.868} & \multirow{3}{*}{.842} \\
\hline & VRA8 & .859 & & & \\
\hline & VRA9 & .799 & & & \\
\hline & SVRE12 & .748 & \multirow{3}{*}{.962} & \multirow{3}{*}{.895} & \multirow{3}{*}{.885} \\
\hline & SVRE13 & .930 & & & \\
\hline & SVRE15 & .917 & & & \\
\hline & OS4 & .924 & \multirow{3}{*}{.986} & \multirow{3}{*}{.959} & \multirow{3}{*}{.952} \\
\hline & OS5 & .946 & & & \\
\hline & OS6 & .928 & & & \\
\hline & RVI7 & .805 & \multirow{3}{*}{.935} & \multirow{3}{*}{.828} & \multirow{3}{*}{.831} \\
\hline & RVI8 & .753 & & & \\
\hline & RVI9 & .854 & & & \\
\hline
\end{tabular}

\section{Procedure and data analysis}

In this study, subjects who participated in VR experience education program on marine safety were asked to explain the contents of the survey, seek cooperation, and respond with a self-administration method. SPSS 20.0 and AMOS 20.0 were used to conduct frequency, confirmatory factor, reliability, correlation, simple regression, and multiple regression analyses on the collected data.

\section{RESULTS}

\section{A. Result of correlation analysis}

As a result of confirming the discriminant validity of each scale, as shown in Table 3, commitment, applicability, and pre-effects of the maritime safety
VR experience showed a positive correlation at the $95 \%$ confidence level for safety consciousness and re-participation behavior. In addition, all correlation coefficients were found to be lower than .80, confirming that there was no multicollinearity problem [16].

Table 3. Result of Correlation Analysis

\begin{tabular}{cccccc}
\hline \hline & FVE & VRA & VRS & CMS & RPB \\
\hline FVE & 1 & & & & \\
VRA & $.719^{* *}$ & 1 & & & \\
VRS & $.705^{* *}$ & $.810^{* *}$ & 1 & & \\
CMS & $.670^{* *}$ & $.735^{* *}$ & $.738^{* *}$ & 1 & 1 \\
RPB & $.756^{* *}$ & $.734^{* *}$ & $.721^{* *}$ & $.779^{* *}$ & 1 \\
\hline \hline
\end{tabular}

$* p<.05,{ }^{*} * p<.01$

FVE: Flow of Virtual reality Experience. VRA: Virtual Reality Applicability.

VRS: Virtual Reality Safety CMS: Consciousness of Marine Safety.

RPB: Re-participation behavior

B. The effect of virtual reality experience education on maritime safety on the effectiveness on safety awareness, satisfaction and reparticipation behavior

The results of analyzing the effect of VR experience education for maritime safety on the effect of participants' maritime safety awareness are as follows $<$ Table $4>$.

As a result of analyzing the effect of VR experience education for maritime safety on the effect of maritime safety awareness of participants, the pre-effect of VR $(\beta=.340)$, VR applicability $(\beta=.311)$, and VR commitment $(\beta=.207)$. was found to have an effect on safety awareness.

Table 4. Results of Multiple regression analysis (A)

\begin{tabular}{ccccc}
\hline \hline Variable & $\mathrm{B}$ & $\mathrm{SD}$ & $\mathrm{B}$ & $\mathrm{t}$ \\
\hline Constant & .591 & .197 & & $3.008^{* *}$ \\
FVE & .201 & .053 & .207 & $3.802^{* * *}$ \\
VRA & .343 & .073 & .311 & $4.711^{* * *}$ \\
PEVE & .337 & .064 & .340 & $5.257^{* * * *}$ \\
\hline \hline$* * p<01, * * * p<.001 \mathrm{~F}=157.740 \mathrm{R}=786, \mathrm{R}^{2}=.618$ & &
\end{tabular}

The results of analyzing the effect of VR 
experience for maritime safety on participants' intention to re-participate are as follows $<$ Table $5>$.

Specifically, VR commitment $(\beta=.418)$, VR applicability $(\beta=.258)$, and the pre-effect of VR $(\beta=.217)$ were found to have an effect on the intention to re-participate.

Table 5. Results of Multiple regression analysis(B)

\begin{tabular}{ccccc}
\hline \hline Variable & $\mathrm{B}$ & $\mathrm{SD}$ & $\mathrm{B}$ & $\mathrm{t}$ \\
\hline Constant & .303 & .191 & & 1.583 \\
FVE & .419 & .051 & .418 & $8.142^{* * *}$ \\
VRA & .295 & .071 & .258 & $4.160^{* * *}$ \\
PEVE & .222 & .062 & .217 & $3.555^{* * * *}$ \\
\hline \hline ** $<01, * * * \mathrm{p}<001 \mathrm{~F}=190.412^{* * *}, \mathrm{R}=.813, \mathrm{R} 2=.662$ & &
\end{tabular}

The result of analyzing the effectiveness of safety awareness of VR experience on re-participation behavior is as follows $<$ Table $6>$.

As a result, the effectiveness of safety awareness of VR experience had a positive effect on reparticipation behavior $(\beta=.721)$.

Table 6. Results of Simple regression analysis

\begin{tabular}{ccccc}
\hline \hline Variable & $\mathrm{B}$ & $\mathrm{SD}$ & $\mathrm{B}$ & $\mathrm{t}$ \\
\hline $\begin{array}{c}\text { Constant } \\
\text { CMS: }\end{array}$ & 1.248 & .198 & & $6.314^{* * * *}$ \\
$\begin{array}{c}\text { Consciousness of } \\
\text { MarineSafety }\end{array}$ & .738 & .041 & .721 & $17.816^{* * *}$ \\
\hline \hline$* * \mathrm{p}<01, * * * \mathrm{p}<.001 \mathrm{~F}=317.420^{* * *}, \mathrm{R}=721, \mathrm{R} 2=.519$ &
\end{tabular}

\section{DISCUSSION}

This study analyzed the effect of VR experience programs for maritime safety on the effectiveness of safety awareness and the effect of participants' reparticipation behavior, and discussed as follows.

First, VR experience program for maritime safety raised participants' safety awareness, and proved to be effective in hands-on education. This confirmed that the participants had some safety needs, and it can be assumed that they were able to achieve safety needs through various programs. In addition, the results of this study were similar to those of a study [3] that reported that maritime disaster experiences had a positive effect on improving marine safety awareness. However, while the existing studies are indirect experience-oriented education, this study is considered to be meaningful in terms of verifying the effectiveness of virtual reality experience programs. Therefore, it is necessary to expand safety education on marine activities based on the spread of more diverse VR experience contents.

Second, the maritime safety VR experience program had a positive effect on the participants' safety awareness. Specifically, it was found that the commitment, applicability, and pre-safety effects of the maritime safety VR experience program had a great influence on the cultivation of safety awareness of visitors. This can be considered a very advanced result in terms of experiencing higher risk stimuli based on VR factors to learn how to effectively cope with dangerous situations or avoid them in dangerous situations [10]. In addition, VR experience program for maritime safety had a positive effect on the participants' re-participation behavior.

Specifically, it was found that the commitment, applicability, and pre-safety effects of the experience program had a positive effect on the satisfaction of the experience and the intention to re-participate. It is similar to the results of previous studies that experiential education and safety activities for maritime safety have a positive effect on safety awareness [3, 5, 7]. Therefore, considering the characteristics of Korea, where various marine sports are developed, the results of this study show that lively risk stimulation can increase the effectiveness of hands-on education by utilizing new VR technology during the 4 th industrial period.

Third, the effectiveness of VR experience program for maritime safety had a positive effect on the participant's re-participation behavior. This is similar to the results of previous studies that the majority of positive expectations and effects affect reparticipation behavior [5]. In particular, it can be seen that the marine safety experience program provided in virtual reality promotes participants' safety awareness and contributes to their revisit.

\section{CONCLUSION}

This study analyzed the relationship between the effectiveness of the safety consciousness of VR experience for maritime safety and the behavior of re-participation, and the conclusions are as follows.

VR experience for maritime safety had a positive effect on the participants' maritime safety awareness and re-participation behavior. The results of this study will contribute to the improvement of maritime safety programs in response to the spread of the marine leisure population in the future. In addition, this study can be seen as more meaningful in terms of highlighting the need to develop safety programs and expand education in Korea, where three sides are the sea. In addition, this study emphasized the 
The Relationship between the Effectiveness of Virtual Reality Experience on Maritime Safety and the Intention to ReParticipate

necessity of producing and operating various contents based on VR.

However, there is a limitation to generalizing the results of this study. Also, further research will require sufficient composition on the level and suitability of the content provided in VR. Lastly, In addition, there will be limitations in generalizing the results of this study because some of the five programs collected data were limited in operation due to COVID-19.

\section{REFERENCES}

[1] Ministry of Oceans and Fisheries (2014). 2nd Marine Tourism Promotion Plan. Available from: https://www. mof.go.kr/article/view.do?articleKey=4639\&boardKey $=22 \&$ menuKey $=386 \&$ currentPageNo=1 Sejong; Minis try of Oceans and Fisheries.

[2] Ministry of Oceans and Fisheries (2019). Statistical Ye arbook of the Oceans and Fisheries. Available from: ht tps://www.mof.go.kr/article/list.do?menuKey=396\&bo $\operatorname{ardKey}=32$ Sejong; Ministry of Oceans and Fisheries.

[3] E. J. Chang, Y. J BAE. (2019). A Study on the Influen ce and Efficiency of Marine Disaster Experience Educ ation on the Consciousness of Marine Safety. Korean Association of Maritime Police Science. 9(3), 67-94

[4] Y. H. Chio(2009). Analysis of the Effect of Experientia $l$ Fire Prevention Training on Safety Awareness. Grad uate School of Public Administration Kyounggi Unive rsity.

[5] J. W. Cho, C. H. LEE. (2016). A Study on the improve ment for Basic·Advance Safety Training Course- Focu sing on the Crew's Fire Fighting Training - The Korea $n$ Society for Fisheries and Marine Sciences Education. 80(2), 417-427.

[6] S. R. Han (2017). Effects of a Hands-on training on Se a survival knowledge, Shipboardfire-fighting knowled ge and Emergency response leadership in Seafarers-Fo cusing on the Advanced safety training for coastwise $v$ essels under the Seamen Act. The Korean Society for Fisheries and Marine Sciences Education. 85(1), 1-12.

[7] J. W. LEE, S. H BAE (2017). A Study on the Need to Improve Water-Related Safety Education- Focusing on the License Acquisitors of Engine-Powered Leisure Watercrafts. The Korean Society for Fisheries and Ma rine Sciences Education. 89(5), 1301-1312.

[8] A. R. Cho. (2017) Development of an effectiveness ass essment method of marine safety experience education program. Graduate School of Interdisciplinary Progra $\mathrm{m}$ in Crisis, Disaster Management Sungkyunkwan Uni versity.

[9] Csikszentmihalyi(2000). Technology of Flow, Book, p 46

[10]K. H. Kim (2019). A Study on the Introduction of VR E ducation Methods for Increasing the Effectiveness of $S$ afety Training On-site. Graduate School of Technolog $\mathrm{y}$ and Business, Kyunghee University

[11]S. I. Mun (2018). A Study for improving the effectivene ss of safety and health education based on the empiric al education utilizing virtual and augmented reality. G raduate School of Technology and Business, Kyunghe e University

[12]M. J. OH, S. D. Kim (2017). The Effect of Satisfaction Factors of a Leisure Sports Event Held at Waterfronto $\mathrm{n}$ Regional Image and Re-Participation Behavior. Jour nal of Sport and Leisure Studies 67, pp.47-56

[13] R. Bagozzi., \& Y. Yi. (1988). On the evaluation of structural equation models. Journal of Academy of Marketing Science, 16, 74-94.

[14] S. J. Hong. (2000). The criteria for selecting appropriate fit indices in structural equation modeling and their rationales. Korean Journal of Clinical Psychology, 19(1), 161-177.

[15] J. Hair, R. Anderson, R. Tatham., \& W. Black. (1998). Multivariate data analysis. $5^{\text {th }} \mathrm{ed}$, Prentice Hall, New Jersey.

[16] J. J. Son(2015), "SPSS/AMOS Statistical Methods ", 21 Century Publishing Company 